\title{
Safe Hydroformylation of Aliphatic Alkene in a Flow Reactor
}

\author{
Hisashi Masui, Eiki Honda, Sakura Niitsu, Mitsuru Shoji, Takashi Takahashi* \\ Department of Pharmaceutical Sciences, Yokohama University of Pharmacy, Yokohama, Japan \\ Email: *ttak@hamayaku.ac.jp
}

How to cite this paper: Masui, H., Honda, E., Niitsu, S., Shoji, M. and Takahashi, T. (2018) Safe Hydroformylation of Aliphatic Alkene in a Flow Reactor. International Journal of Organic Chemistry, 8, 135-141. https://doi.org/10.4236/ijoc.2018.81009

Received: November 30, 2017

Accepted: March 6, 2018

Published: March 9, 2018

Copyright $\odot 2018$ by authors and Scientific Research Publishing Inc. This work is licensed under the Creative Commons Attribution International License (CC BY 4.0).

http://creativecommons.org/licenses/by/4.0/

(c) (i) Open Access

\begin{abstract}
Despite hydroformylation being a very efficient method for the transformation of alkenes, it is not commonly employed in laboratories owing to the flammable/toxic nature of hydrogen and carbon monoxide gases and the necessity of high-pressure equipment in a batch system. Flow chemistry often raises the safety profiles against high-pressure and toxic gases because the diameter of the flow reactor is small. Herein, we show that aliphatic alkenes can be safely hydroformylated in a flow reactor. In our flow method, although the target hydroformylated product was obtained in a low yield (19\%), toxic gases were safely treated using a flow reactor. Better yields could possibly be achieved by recycling of the unreacted alkene.
\end{abstract}

\section{Keywords}

Hydroformylation, Flow Synthesis, Alkene, Carbon Monoxide, Aldehyde

\section{Introduction}

Petrochemistry is highly significant for the chemical industry, since petroleum provides raw materials for the fabrication of plastics and other ubiquitous products [1]. In particular, alkenes in petroleum are of great value, because they are easier to transform than alkanes. The typical methods of converting alkene into synthetically versatile carbonyl compounds are hydroformylation (to afford aldehydes) [2] [3] [4] [5] and Wacker oxidation (to afford methyl ketones) [6] [7]. These reactions are industrially useful, since the requisite gaseous reagents are often very inexpensive and work-up after the reaction can be easily performed by their diffusion. Hydroformylation has become one of the largest industrially applied processes, and more than seven million tons of oxygenated products such as aldehydes and alcohols are produced per year [8]. Recently, hydrofor- 
mylation has also been used for the synthesis of natural products [9] [10] [11] [12] and heterocyclic compounds [13] [14] [15] [16], as exemplified by our hydroformylation-based synthesis of $( \pm)$-muscone [9]. Despite hydroformylation being a very efficient method for the transformation of alkenes, it is not commonly employed in laboratories, because of the following major problems: 1) the need for safe treatment of flammable/toxic nature of hydrogen and carbon monoxide, and the requirement of high-pressure batch equipment; 2) low hydroformylation yield; 3) the necessity to separate the desired aldehyde and unreacted alkene; and 4) need to recycle of the unreacted alkene.

We herein focused on conducting safe hydroformylation. Recently, flow chemistry has emerged as an important alternative to conventional batch chemistry [17] [18] [19] [20], frequently enhancing the safety profiles of synthetic processes. It has also emerged as an effective method for conducting hazardous reactions (such as hydroformylation) involving toxic reagents or high-pressure gases [21] [22]. To the best of our knowledge, only one example of hydroformylation in a flow reactor has been reported earlier [23], which was conducted by Ley et al., who performed safety hydroformylation of styrene analogs by utilizing a tube-in-tube reactor [24] [25] [26] [27]. To expand the above field, we report the safe hydroformylation of oct-1-ene, a relatively low-reactive aliphatic alkene.

\section{Materials and Methods}

\subsection{General}

NMR spectra were recorded on a JEOL Model ECA-500 instrument, and chemical shifts were reported in parts per million ( $\mathrm{ppm}$ ) relative to internal standard (tetramethylsilane; $0.0 \mathrm{ppm}$ ) or solvent $\left(\mathrm{CDCl}_{3} ; 7.26 \mathrm{ppm}\right.$ for ${ }^{1} \mathrm{H}$ NMR and 77.1 ppm for ${ }^{13} \mathrm{C}$ NMR) peaks. ${ }^{1} \mathrm{H}$ NMR spectral data were reported as chemical shift $(\delta, \mathrm{ppm})$, multiplicity (s, singlet; $\mathrm{d}$, doublet; $\mathrm{t}$, triplet; $\mathrm{q}$, quartet; sp, septet; $\mathrm{m}$, multiplet; br, broad), coupling constant $(J, \mathrm{~Hz})$, and integral value. ${ }^{13} \mathrm{C}$ NMR data were reported as chemical shift $(\delta, \mathrm{ppm})$ followed by multiplicity and coupling constants where applicable. All reactions were monitored by thin-layer chromatography using $0.25 \mathrm{~mm}$ E. Merck silica gel plates $\left(60 \mathrm{~F}_{254}\right)$, with visualization performed by UV light $(254 \mathrm{~nm})$ irradiation or staining with $p$-anisaldehyde, ceric sulfate, or $10 \%$ ethanolicphosphomolybdic acid followed by heating. Column chromatography was performed using silica gel (Chromatorex PSQ 100B, Fuji Silysia Chemical Ltd.). All reagents and chemicals were purchased from Tokyo Chemical Industry Co., Ltd., and used as received.

\subsection{Flow Reactor Setup}

The flow system used in this work (Figure 1) comprised a stainless steel T-shaped micromixer (inner diameter: $500 \mu \mathrm{m}$; YMC Co., Ltd.) and a stainless steel tube (inner diameter: $1000 \mu \mathrm{m}$; GL Sciences, Inc.). Back-pressure regulator was purchased from GL Sciences, Inc. Solutions were introduced using a syringe pump (Harvard PHD ULTRA) equipped with gastight syringes (SGE Analytical 


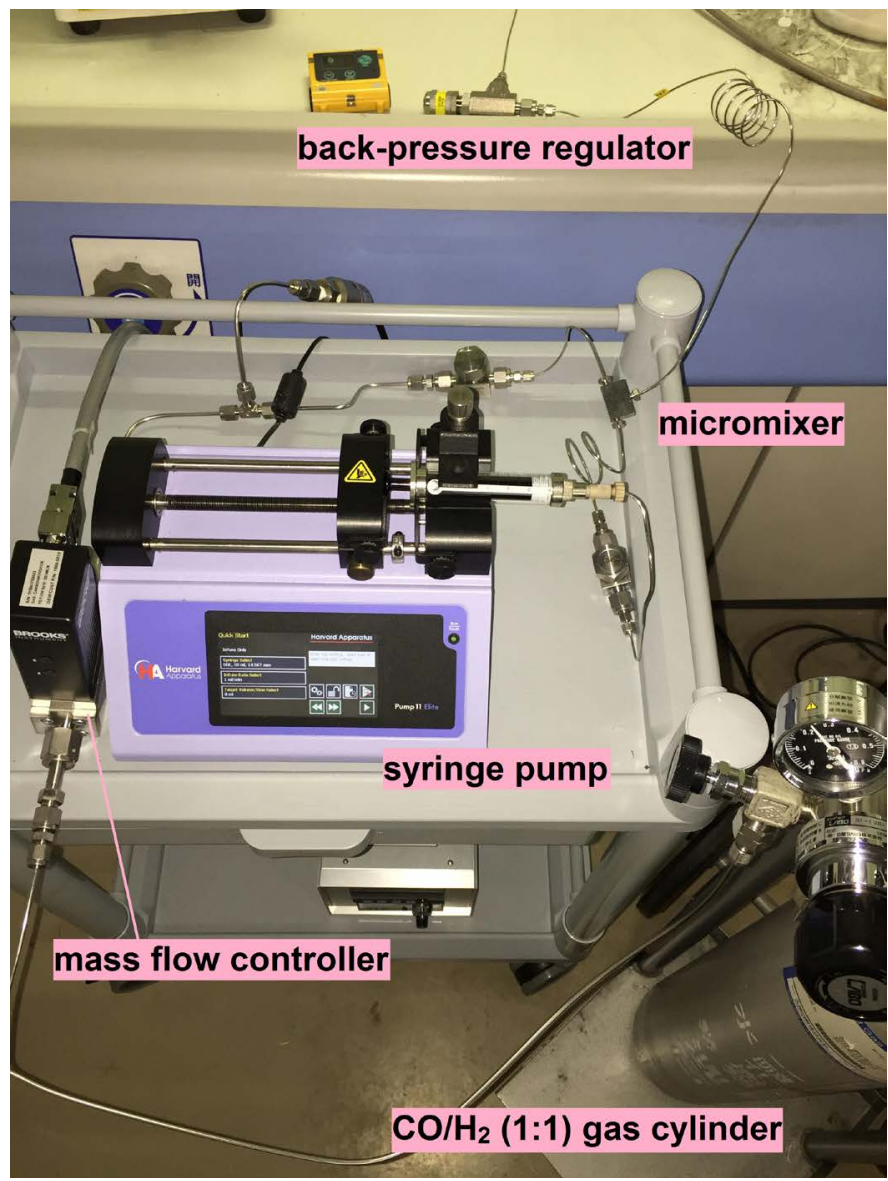

Figure 1. Flow system used for hydroformylation.

Science Pty., Ltd.). Hydrogen and carbon monoxide were delivered to the micromixer at a constant rate utilizing a mass flow controller (Brooks Instrument) from a $\mathrm{CO} / \mathrm{H}_{2}(1: 1)$ gas cylinder. System pressure was controlled by using a back-pressure regulator and monitored using a pressure sensor attached to the mass flow controller.

\subsection{General Hydroformylation Procedure}

To a solution of oct-1-ene ( $71.5 \mathrm{mg}, 0.637 \mathrm{mmol}, 1.00$ equiv.) in solvent (4.00 $\mathrm{mL}$ ) were added $\mathrm{Rh}(\mathrm{CO}) \mathrm{H}\left(\mathrm{PPh}_{3}\right)_{3}(11.7 \mathrm{mg}, 0.0127 \mathrm{mmol}, 0.0200$ equiv.) and Xantphos (28.8 mg, $0.0497 \mathrm{mmol}, 0.0780$ equiv.) at room temperature. The obtained mixture was introduced into the $\mathrm{T}$-shaped micromixer using the syringe pump (flow rate) and passed through the stainless steel tube (inner diameter: $1000 \mu \mathrm{m}$, length: $8.0 \mathrm{~m}$ ) at $100^{\circ} \mathrm{C}$ under $\mathrm{CO} / \mathrm{H}_{2}(1: 1)$ (flow rate $200 \mathrm{~mL} / \mathrm{min}, 18$ atm). The product yield was determined by gas chromatography.

\section{Results and Discussion}

The flow reactor for the hydroformylation of oct-1-ene(1) is schematically depicted in Figure 2. Initially, a solution of oct-1-ene, $\mathrm{Rh}(\mathrm{CO}) \mathrm{H}\left(\mathrm{PPh}_{3}\right)_{3}$, and Xantphos [28] in toluene was introduced into the T-shaped micromixer at $100^{\circ} \mathrm{C}$ 
under a $\mathrm{CO} / \mathrm{H}_{2}$ (flow rate $200 \mathrm{~mL} / \mathrm{min}, 18$ atm) atmosphere using the syringe pump, and hydroformylation was carried out by passing the above solution through the stainless steel tube (inner diameter: $1000 \mu \mathrm{m}$, length: $8.0 \mathrm{~m}$ ) to afford nonanal, followed by optimization of the flow rate $(\mathrm{mL} / \mathrm{min})$ of the solution.

Flow rate of the solution was examined at $0.10,0.40,0.70$, and $1.0 \mathrm{~mL} / \mathrm{min}$ (Figure 3). Among the conditions, the best yield of nonanal (8\%) was achieved at an intermediate flow rate of $0.40 \mathrm{~mL} / \mathrm{min}$, as observed by Ley and coworker for the hydroformylation of styrene analogs [23]. This behavior was ascribed to high flow rates, which resulted in insufficient reaction times; low flow rates did not allow the gaseous reagents and the substrate solution to mix efficiently.

Subsequently, we optimized the solvent (Table 1). The best yield (19\%) was

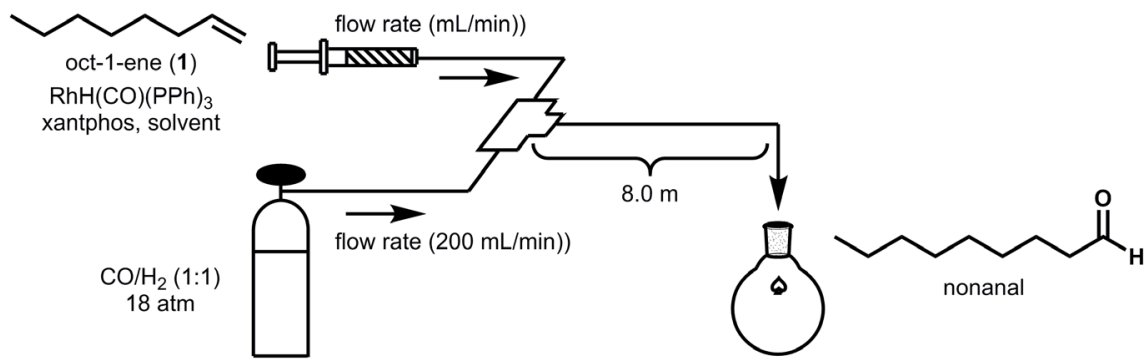

Figure 2. Schematic representation of the flow reactor.

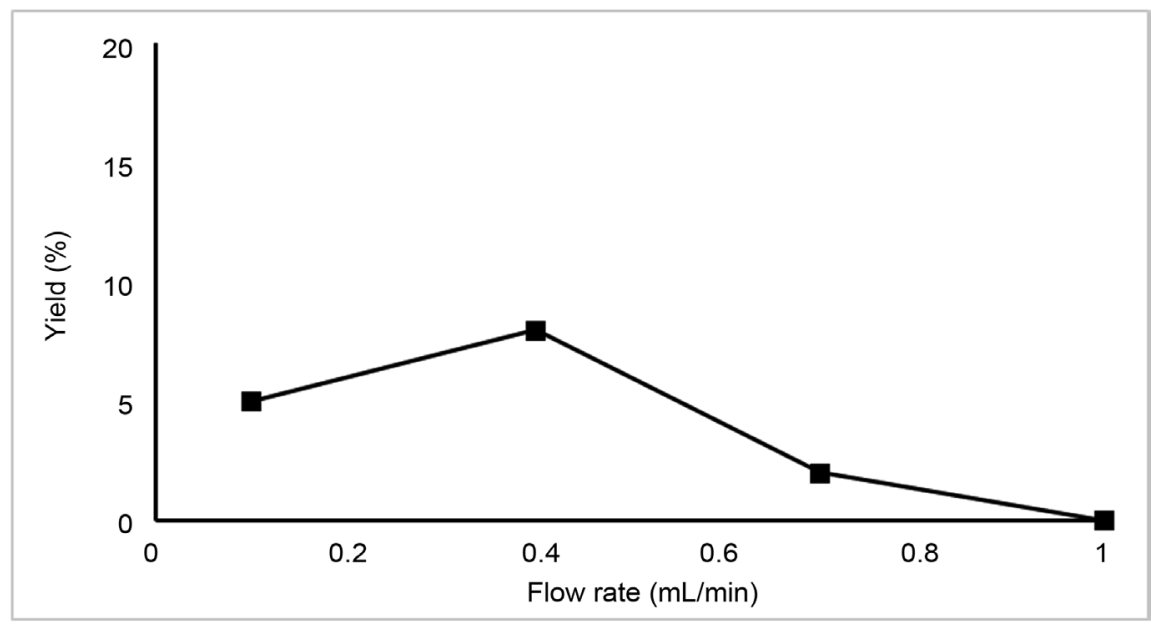

Figure 3. Optimization of flow rate for hydroformylation in a flow reactor.

Table 1. Solvent optimization for hydroformylation in a flow reactor.

\begin{tabular}{ccc}
\hline Entry $^{\mathrm{a}}$ & Solvent & Yield $^{\mathrm{b}}$ \\
\hline 1 & chlorobenzene & $19 \%$ \\
2 & toluene & $8 \%$ \\
3 & 1,4 -dioxane & $4 \%$
\end{tabular}

a. Reaction conditions: $100^{\circ} \mathrm{C}, \mathrm{CO} / \mathrm{H}_{2}$ pressure: $18 \mathrm{~atm}$, flow rate: $0.40 \mathrm{~mL} / \mathrm{min}$, and tube length: $8.0 \mathrm{~m}$; b. Yield was determined by gas chromatography. 
accomplished in the case of chlorobenzene, whereas toluene and 1,4-dioxane gave lower yields of 8 and 4\%, respectively. The above yield of $19 \%$ can be further improved by recycling the unreacted substrate, which makes this method suitable for large-scale production as it allows the reaction work-up to be easily performed by gaseous reagent diffusion. The recycling of the unreacted substrate was achieved in batch system by the normal distillation. The development of the recycling system in flow reactor is currently under way.

\section{Conclusion}

In summary, we successfully and safely hydroformylated an aliphatic alkene in a flow reactor. The maximum yield of the target aldehyde (19\%) was achieved at $0.40 \mathrm{~mL} / \mathrm{min}$ flow rate in chlorobenzene. The developed method can be easily up scaled, because the reaction work-up can be easily performed by gaseous reagent diffusion. Although the yield of the target aldehyde is low, it can be improved by recycling the unreacted alkene.

\section{Acknowledgements}

This work was supported by the Asahi Glass Foundation. We would like to thank Prof. Ilhyong Ryu and Dr. Takahide Fukuyama at Osaka Prefecture University for assistance with the flow reactor setup. We also thank Dr. Kenichiro Yagi at the Yokohama University of Pharmacy for assistance with GC analysis.

\section{References}

[1] Speight, J.G. (2014) The Chemistry and Technology of Petroleum. 5th Edition, CRC Press, Taylor \& Francis Group, Boca Raton, FL.

[2] Adkins, H. and Krsek, G. (1949) Hydroformylation of Unsaturated Compounds with a Cobalt Carbonyl Catalyst. Journal of the American Chemical Society, 71, 3051-3055. https://doi.org/10.1021/ja01177a032

[3] Evans, D., Osborn, J.A. and Wilkinson, G. (1968) Hydroformylation of Alkenes by Use of Rhodium Complex Catalysts. Journal of the Chemical Society A, 33, 3133-3142. https://doi.org/10.1039/j19680003133

[4] Breit, B. (2003) Synthetic Aspects of Stereoselective Hydroformylation. Accounts of Chemical Research, 36, 264-275. https://doi.org/10.1021/ar0200596

[5] Franke, R., Selent, D. and Borner, A. (2012) Applied Hydroformylation. Chemical Reviews, 112, 5675-5732. https://doi.org/10.1021/cr3001803

[6] Smidt, J., Hafner, W., Jira, R., Sieber, R., Sedlmeier, J. and Sabel, A. (1962) The Oxidation of Olefins with Palladium Chloride Catalysts. Angewandte Chemie International Edition, 1, 80-88. https://doi.org/10.1002/anie.196200801

[7] Tsuji, J. (1984) Synthetic Applications of the Palladium-Catalyzed Oxidation of Olefins to Ketones. Synthesis, 1984, 369-384. https://doi.org/10.1055/s-1984-30848

[8] Weissermel, K. and Arpe, H.-J. (1988) Industrielle Organische Chemie. VCH Publishers, Weinheim.

[9] Takahashi, T., Machida, K., Kido, Y., Nagashima, K., Ebata, S. and Doi, T. (1997) Hydroformylation of $\omega$-Functionalized 1,1-Disubstituted Alkenes and Its Use Toward the Synthesis of ( \pm )Muscone. Chemistry Letters, 26, 1291-1292. 
https://doi.org/10.1246/cl.1997.1291

[10] Eilbracht, P., Barfacker, L., Buss, C., Hollmann, C., Kitsos-Rzychon, B.E., Kranemann, C.L., Rische, T., Roggenbuck, R. and Schmidt, A. (1999) Tandem Reaction Sequences under Hydroformylation Conditions: New Synthetic Applications of Transition Metal Catalysis. Chemical Reviews, 99, 3329-3365. https://doi.org/10.1021/cr970413r

[11] Liu, P. and Jacobsen, E.N. (2001) Total Synthesis of (+)-Ambruticin. Journal of the American Chemical Society, 123, 10772-10773. https://doi.org/10.1021/ja016893s

[12] Airiau, E., Spangenberg, T., Girard, N., Breit, B. and Mann, A. (2010) Short Access to (+)-Lupinine and (+)-Epiquinamide via Double Hydroformylation. Organic Letters, 12, 528-531. https://doi.org/10.1021/ol902718q

[13] McDonald, R.I., Wong, G.W., Neupane, R.P., Stahl, S.S. and Landis, C.R. (2010) Enantioselective Hydroformylation of $N$-Vinyl Carboxamides, Allyl Carbamates, and Allyl Ethers Using Chiral Diazaphospholane Ligands. Journal of the American Chemical Society, 132, 14027-14029. https://doi.org/10.1021/ja106674n

[14] Chiou, W.-H., Mizutani, N. and Ojima, I. (2007) Highly Efficient Synthesis of Azabicyclo[x.y.0]alkane Amino Acids and Congeners by Means of Rh-Catalyzed Cyclohydrocarbonylation. Journal of Organic Chemistry, 72, 1871-1882. https://doi.org/10.1021/jo061692y

[15] Campi, E.M., Jackson, W.R. and Nilsson, Y. (1991) A Hydroformylation Route to $\beta$-Substituted Pyrroles. Tetrahedron Letters, 32, 1093-1094. https://doi.org/10.1016/S0040-4039(00)74496-0

[16] Wuts, P.G.M., Obrzut, M.L. and Thompson, P.A. (1984) Hydroformylation as a Simple and Efficient One Carbon Homologation of Homoallylic Alcohols. Synthesis of Prelog-Djerassi Lactone. Tetrahedron Letters, 25, 4051-4054. https://doi.org/10.1016/S0040-4039(01)90179-0

[17] Yoshida, J., Takahashi, Y. and Nagaki, A. (2013) Flash Chemistry: Flow Chemistry That Cannot Be Done in Batch. Chemical Communications, 49, 9896-9904. https://doi.org/10.1039/C3CC44709J

[18] Movsisyan, M., Delbeke, E.I.P., Berton, J.K.E.T., Battilocchio, C., Ley, S.V. and Stevens, C.V. (2016) Taming Hazardous Chemistry by Continuous Flow Technology. Chemical Society Reviews, 45, 4892-4928. https://doi.org/10.1039/C5CS00902B

[19] Fuse, S., Mifune, Y. and Takahashi, T. (2014) Efficient Amide Bond Formation through a Rapid and Strong Activation of Carboxylic Acids in a Microflow Reactor. Angewandte Chemie International Edition, 53, 851-855. https://doi.org/10.1002/anie.201307987

[20] Fuse, S., Tanabe, N., Yoshida, M., Yoshida, H., Doi, T. and Takahashi, T. (2010) Continuous-Flow Synthesis of Vitamin $\mathrm{D}_{3}$. Chemical Communications, 46, 8722-8724. https://doi.org/10.1039/c0cc02239j

[21] Mallia, C.J. and Baxendale, I.R. (2016) The Use of Gases in Flow Synthesis. Organic Process Research \& Development, 20, 327-360. https://doi.org/10.1021/acs.oprd.5b00222

[22] Wegner, J., Ceylan, S. and Kirschning, A. (2011) Ten Key Issues in Modern Flow Chemistry. Chemical Communications, 47, 4583-4592. https://doi.org/10.1039/c0cc05060a

[23] Kasinathan, S., Bourne, S., Tolstoy, P., Koos, P., O’Brien, M., Bates, R.W., Baxendale, I.R. and Ley, S.V. (2011) Syngas-Mediated C-C Bond Formation in Flow: Selective Rhodium-Catalysed Hydroformylation of Styrenes. Synlett, 2011, 2648-2651. 
https://doi.org/10.1055/s-0031-1289292

[24] Koos, P., Gross, U., Polyzos, A., O’Brien, M., Baxendale, I.R. and Ley, S.V. (2011) Teflon AF-2400 Mediated Gas-Liquid Contact in Continuous Flow Methoxycarbonylations and In-Line FTIR Measurement of CO Concentration. Organic \& Biomolecular Chemistry, 9, 6903-6908. https://doi.org/10.1039/c1ob06017a

[25] Polyzos, A., O’Brien, M., Peterson, T.P., Baxendale, I.R. and Ley, S.V. (2011) The Continuous-Flow Synthesis of Carboxylic Acids Using $\mathrm{CO}_{2}$ in a Tube-In-Tube Gas Permeable Membrane Reactor. Angewandte Chemie International Edition, 50, 1190-1193. https://doi.org/10.1002/anie.201006618

[26] O’Brien, M., Baxendale, I.R. and Ley, S.V. (2010) Flow Ozonolysis Using a Semipermeable Teflon AF-2400 Membrane To Effect Gas-Liquid Contact. Organic Letters, 12, 1596-1598. https://doi.org/10.1021/ol100322t

[27] O’Brien, M., Taylor, M., Polyzos, A., Baxendale, I.R. and Ley, S.V. (2011) Hydrogenation in Flow: Homogeneous and Heterogeneous Catalysis Using Teflon AF-2400 to Effect Gas-Liquid Contact at Elevated Pressure. Chemical Science, 2, 1250-1257. https://doi.org/10.1039/c1sc00055a

[28] Kranenburg, M., van der Burgt, Y.E.M., Kamer, P.C.J., van Leeuwen, P.W.N.M., Goubitz, K. and Fraanje, J. (1995) New Diphosphine Ligands Based on Heterocyclic Aromatics Inducing Very High Regioselectivity in Rhodium-Catalyzed Hydroformylation. Organometallics, 14, 3081-3089. https://doi.org/10.1021/om00006a057 